\title{
QUESTIONS AND ANSWERS REGARDING ACTIONS TO TAKE WHEN ENDING SHELTER-IN-PLACE
}

Barry Shumpert

OAK RIDGE NATIONAL LABORATORY 


\title{
DOCUMENT AVAILABILITY
}

Reports produced after January 1, 1996, are generally available free via the U.S. Department of Energy (DOE) Information Bridge.

Web site http://www.osti.gov/bridge

Reports produced before January 1, 1996, may be purchased by members of the public from the following source.

\author{
National Technical Information Service \\ 5285 Port Royal Road \\ Springfield, VA 22161 \\ Telephone 703-605-6000 (1-800-553-6847) \\ TDD 703-487-4639 \\ Fax 703-605-6900 \\ E-mail info@ntis.fedworld.gov \\ Web site http://www.ntis.gov/support/ordernowabout.htm
}

Reports are available to DOE employees, DOE contractors, Energy Technology Data Exchange (ETDE) representatives, and International Nuclear Information System (INIS) representatives from the following source.

Office of Scientific and Technical Information

P.O. Box 62

Oak Ridge, TN 37831

Telephone 865-576-8401

Fax 865-576-5728

E-mail reports@adonis.osti.gov

Web site http://www.osti.gov/contact.html

This report was prepared as an account of work sponsored by an agency of the United States Government. Neither the United States Government nor any agency thereof, nor any of their employees, makes any warranty, express or implied, or assumes any legal liability or responsibility for the accuracy, completeness, or usefulness of any information, apparatus, product, or process disclosed, or represents that its use would not infringe privately owned rights. Reference herein to any specific commercial product, process, or service by trade name,

trademark, manufacturer, or otherwise, does not necessarily constitute or imply its endorsement, recommendation, or favoring by the United States Government

or any agency thereof. The views and opinions of authors expressed herein do not necessarily state or reflect those of the United States Government or any agency thereof. 
ORNL/TM-2003/230

\title{
QUESTIONS AND ANSWERS REGARDING ACTIONS TO TAKE
} WHEN ENDING SHELTER-IN-PLACE

\author{
Barry Shumpert \\ OAK RIDGE NATIONAL LABORATORY
}

Date Published: September 2003

\begin{abstract}
Prepared for
Department of Homeland Security

Chemical Stockpile Emergency Preparedness Program

Protective Action Working Integrated Process Team
\end{abstract}

Prepared by

OAK RIDGE NATIONAL LABORATORY

Oak Ridge, Tennessee 37831

managed by

UT-BATTELLE, LLC

for the

U.S. DEPARTMENT OF ENERGY

under contract DE-AC05-00OR22725 


\section{CONTENTS}

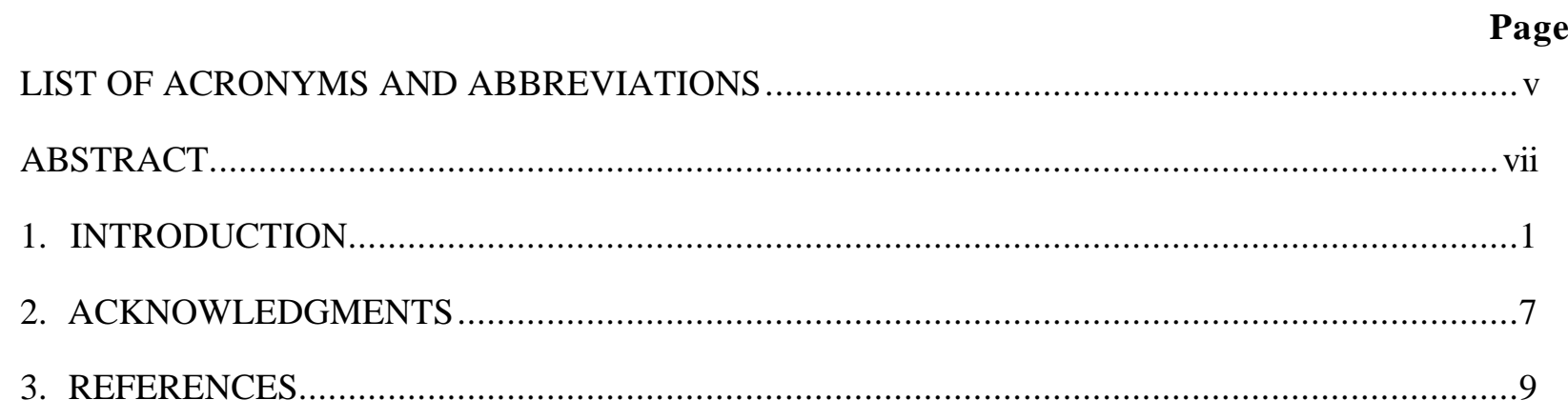




\section{LIST OF ACRONYMS AND ABBREVIATIONS}

CSEPP

VX
Chemical Stockpile Emergency Preparedness Program a nerve agent 


\begin{abstract}
Shelter-in-place has found increasing acceptance as an effective protective action option for communities participating in the Chemical Stockpile Emergency Preparedness Program. Studies have confirmed that it can provide optimum protection under certain accident conditions. However, emergency managers and planners, as well as the public, continue to be troubled by the need to end sheltering when the plume has passed in order to avoid sustained exposure to the small amount of agent that has penetrated the shelter. One of the concerns posed by this necessity is uncertainty regarding what hazards will then be faced in the environment outside the shelter and what actions can be taken to avoid those hazards.

This report attempts to address those uncertainties. It recognizes that there is an extremely low probability that the environment outside the shelter will be contaminated with chemical agent residue. However, as people comply with an official recommendation to leave their shelters, they probably can't be certain that the environment is free from contamination. Therefore, this report identifies and explains specific and simple actions they can take to avoid the possibility of exposure to chemical agent hazards outside their shelters. It addresses such issues as the actions people should take upon ending shelter-in-place, what clothing they should wear, how they should handle animals, and what they should do about food in their homes and produce in their gardens.
\end{abstract}




\section{INTRODUCTION}

Since the creation of the Chemical Stockpile Emergency Preparedness Program (CSEPP), participating communities have worked to determine what actions their citizens should take to best protect themselves from an unlikely accident involving chemical warfare agent. Planners and officials were initially skeptical of the option of shelter-in-place, largely because it was unfamiliar and answers were not readily available to their questions regarding its effectiveness and methods of implementation. As time has passed, however, many of these questions have been answered, and shelter-in-place has been shown to provide optimum protection under certain accident conditions. It has increasingly been accepted in CSEPP as an effective protective measure.

One continuing problem regarding shelter-in-place has been the necessity to open up and/or leave the shelter when the chemical agent plume has passed by. Part of the difficulty posed by this problem is in knowing what people should do at that time. The public wants to know how safe the outside environment will be when they end sheltering and what steps they should take to avoid exposure in that environment.

This paper attempts to answer the major outstanding questions about what to do when ending shelterin-place. Its goal is to help people minimize the possibility of exposure as they leave their shelters and to increase their confidence that shelter-in-place is an effective response to a chemical agent release.

\section{Why can't I stay in my closed shelter after the plume has passed by?}

As the end of a chemical agent plume passes by, the concentration of the chemical in the outside air normally drops fairly quickly to a very low level. Inside the shelter building, however, a small amount of the chemical agent will have seeped in while the plume was present. If the shelter remains closed, it will take this agent a long time to completely leak back out of the building, and anyone who remains inside will continue to be exposed to the low concentration of agent. It is important for you to avoid this additional exposure by opening the shelter promptly when emergency officials give the all-clear signal. (Some facilities, such as schools and hospitals, are equipped with pressurization and filtration systems that prevent chemical agent from seeping into the building. Shelters of this special type do not have to be opened up as soon as the plume has passed by.)

\section{What will the environment be like outside when I end sheltering?}

There is no way to give a precise answer to this question beforehand. In almost all cases, any chemical agent reaching off-post areas will be in the form of a cloud of vapors. By the time emergency officials advise you to end sheltering, either this cloud will have left your area or the concentration of agent will be lower outside than inside your shelter. There will be little chance that you will be exposed to a harmful amount of agent outside (Argonne National Laboratory 2001). However, in very unusual cases, chemical agent could be deposited on outside surfaces. This could happen if a very large amount of mustard agent or nerve agent VX were released in the form of fine droplets or particles. It could also occur following a vapor release of one of these agents under very unusual weather conditions. In these highly unlikely cases, you would need to minimize contact with outside surfaces to avoid the possibility of exposure. When you are instructed to leave your shelter, you may not know which of these situations you face. Therefore, it is recommended that you take full precautions to minimize any possible exposure outside the shelter. The following questions and answers tell you how to do that.

\section{What should I do when told to end shelter-in-place-just open up the shelter's windows and doors or relocate to an unaffected area?}

You should follow the recommendations of your local emergency officials. When they advise you to end shelter-in-place, they are to tell you what actions you should take. If they advise you to ventilate your shelter but remain in the building, you can minimize your exposure to any chemical agent still 
inside by staying near open doors and windows on the upwind side of the building (that is, the side of the building facing the direction the wind is blowing from). If emergency officials tell you to leave the building, you should minimize your contact with outside surfaces to protect against the remote possibility that chemical warfare agent has settled on them. You should also avoid low-lying areas, such as ditches and deep valleys, in case agent vapors have pooled there.

\section{Should I take a shower before leaving?}

Taking a quick shower before leaving the shelter is not required, but it is a good idea. If you choose to take a shower, wait until authorities advise you to end shelter-in-place. Then open up the shelter building completely, making sure that bathroom windows are fully open and exhaust fans are running. These actions will help clear out any minor amount of agent that may have accumulated in the air of the bathroom. You should shower with lukewarm water and start by washing your face and hair. You can use soap if available, but plain water is also effective. There is no need to use chlorine bleach as a decontaminant. You should not use hot water and should not scrub the skin too vigorously since these actions can cause your skin to absorb any chemical agent residue more quickly.

\section{Should I change clothes before leaving?}

Changing clothes before leaving the shelter can be beneficial in case a small amount of agent vapor or aerosol has become trapped in your clothing. You should open up the shelter completely before starting to change clothes. If time permits, you may wish to place all the clothes removed by shelter occupants in one place so they can be identified and disposed of later.

\section{How should I dress?}

When you exit your shelter you should wear shoes that cover your entire foot (in other words, no sandals). While it is unlikely that you will need any special clothing for protection, you can be extra safe by wearing clothes that minimize the amount of skin exposed, such as long pants, long-sleeves, and a hat or cap. Household plastic gloves will provide some protection in case chemical agent droplets or particles have been deposited on any outside surfaces you must touch. If such gloves are not available, duct tape can be applied to the fingers and palms of leather or cotton gloves.

\section{What clothes in the house are safe to wear?}

Garments inside closed drawers and closets should harbor very little, if any, chemical agent. To be extra cautious you may wish to avoid the garment on top of the stack inside each drawer. Avoid garments from open closets or closets which have ventilation vanes in the doors. If you prepared a disaster supply kit before the emergency, any clothes in the kit should be safe for wear.

\section{What items should I take with me if I relocate to an unaffected area after sheltering?}

When you relocate after sheltering, you should take fewer items with you than if you had evacuated immediately when you heard about the chemical agent release. For instance, if you had evacuated earlier, you might have taken pillows and blankets. But after sheltering, such items might hold small amounts of chemical agent that could present a hazard. When you relocate to an unaffected area after sheltering, you should take items that are critically needed, such as your wallet, house and car keys, eyeglasses, and medicines that were stored in airtight containers. Any of these items that were not with you inside the shelter room can be washed in hot soapy water or household chlorine bleach to remove any traces of chemical agent. Do not take any food or water unless it is critically needed, for instance by infants or small children. (Methods of selecting food and decontaminating its packaging are discussed later.) If you have a pre-prepared disaster supply kit, it should be safe to carry if it is stored in a closed, impervious bag or container. A disaster supply kit should include a batterypowered radio, flashlight, extra batteries, food, water, and clothing for household members. 


\section{Should I cover my nose and mouth with a handkerchief?}

Breathing through a handkerchief or other cloth will not provide any significant protection from chemical agent vapors. However, it may provide some protection against airborne aerosols, which are miniscule droplets or particles of liquid or dry agent. Thus, covering your mouth and nose with a handkerchief or other cloth may be beneficial if some chemical agent aerosols remain in the air or if your movements outside the shelter stir up agent particles that had been deposited onto surfaces in the area.

\section{What can I touch outside the shelter?}

While it is very unlikely that outside surfaces will be contaminated, the remote possibility of contamination does exist for mustard agent and the nerve agent VX. Surfaces can be contaminated if one of these agents is released in aerosol form or if weather conditions are right to cause agent vapors to condense and settle. For maximum safety, you should touch as few outside surfaces as possible. Also, wearing long garments and plastic gloves (as discussed above) will provide some additional protection in case agent deposition has occurred.

\section{What should be done about pets that were inside the shelter while the plume passed by? Should they be bathed?}

There is a slight possibility that pets which were with you in the shelter room will have traces of chemical agent vapor or aerosol in their fur or feathers or on their skin. Such residual contamination could be harmful to children or others who then played with the animal. Rinsing the pet thoroughly with water will remove the agent. Soap can be used if available. The quickest way to handle this situation may be to take the pet with you when you shower as described earlier. Be sure to wait until officials advise you to end shelter-in-place, then open up the shelter building completely before taking care of your pets.

\section{What should I do about pets and livestock that were left outside?}

The most important thing for you to do on ending shelter is to follow the recommendations of your local emergency management officials. If they advise you to relocate immediately to an unaffected area, do not delay while you take care of outside animals. Do not allow outside pets to approach you; chemical agent could be present in their fur. If emergency management officials don't recommend immediate relocation, you can decontaminate outside animals by washing them with soap and water followed by a plain water rinse. Be very careful not to contaminate yourself in the process. Wear a raincoat and plastic gloves and, if possible, use a long handled brush to wash the animal. Such measures are probably worth the effort and risk only for prized pets and valuable livestock. Be sure to provide fresh, clean water for outside animals, after washing the drinking vessels with hot soapy water or household chlorine bleach.

\section{If I relocate to an unaffected area, where should I go?}

When relocating after ending shelter-in-place, you should follow the recommendations of your local emergency management officials. They will tell you the quickest and safest route out of the area affected by the chemical agent release. You should check in at a designated reception center even if you do not plan to stay in a mass care shelter. (Relocation routes and reception centers may not be the same as those used earlier by evacuees.) Staff at the reception center will provide practical information about the emergency situation, determine if you need decontamination or medical treatment, and add your name to their register so that friends and family members who check will know you are safely out of the hazard area.

\section{Can I walk through vegetated areas to get to my car?}

There is a remote chance that grass and other vegetation could be contaminated following a release of mustard agent or nerve agent VX. In this unlikely situation, walking through the grass could cause 
agent to be resuspended in the air, resulting in exposure to you and the people with you. Similarly, walking under trees could expose you to contamination falling or dripping from leaves and branches. The safest course of action is to stay on hard, flat surfaces, such as concrete; avoid walking under overhanging vegetation; and create as little disturbance as possible as you move.

\section{Will my car be contaminated? The outside, such as door handles? The interior?}

Following a release of a mustard agent or nerve agent VX, there is a very slight possibility that the exterior of your automobile could be contaminated if it was parked outside while the plume was passing through the area. To minimize the chance of exposure to deposited agent particles, you should wear plastic gloves or use an uncontaminated piece of plastic sheeting to shield your hand when opening car doors. If the vehicle's windows were closed during the release of agent, the chance of deposited contamination inside is even more remote. However, it is possible that agent vapors may have become trapped in the air inside a car parked in the open. You can clear them out by opening all the doors and allowing the interior to air out for a few minutes before entering the car.

\section{If I relocate to an unaffected area, do I leave the car windows up or down? Do I use the heater, air conditioner, or vents?}

If you relocate after ending shelter-in-place, you should lower all the windows in your vehicle unless local emergency management officials advise otherwise. The concentration of agent in the outside air should be near zero. Opening the windows will allow this clean air to enter the car and completely flush out any agent vapor that had been trapped inside the vehicle. Under most conditions, the heater, air conditioner, and vent controls should be switched to the "off" position before the car is started. If it is necessary to use one of these systems because of extreme temperatures, the controls should be turned on and the system allowed to run for a few minutes before passengers enter the vehicle.

\section{Will the water supply be contaminated?}

It is practically impossible for groundwater sources to be contaminated by an airborne chemical agent release. Significant contamination of surface water sources is also unlikely because the large amount of water in surface reservoirs would greatly dilute any concentration of agent deposited on them. The water system extending into your home is pressurized, which would prevent any agent from entering the pipes. Consequently, you can safely drink and use the water system in your home unless local emergency officials advise you not to. You should take care, however, to be sure the glass or cup you drink from is free from contamination. These items can be washed thoroughly in hot soapy water or household chlorine bleach to remove any traces of chemical agent.

\section{Is food in the house safe to eat?}

According to CSEPP Planning Guidance, your local and state emergency management officials will quarantine all food in the area affected by the release until they can determine whether it is safe to consume. Do not eat any food that was in the affected area until the authorities tell you it is safe to do so. If it is critically necessary to feed an infant or small child before getting out of the hazard area, food from a closed refrigerator or freezer should be safe. Other food in unopened, sealed glass or foil containers will be safe after the container is thoroughly washed in hot soapy water or chlorine bleach. Be sure that dishes and utensils are similarly washed.

\section{Is it all right to eat the vegetables in my garden? Are my crops safe to eat or sell to others?}

The safety of agricultural produce (including both commercially grown crops and fruits and vegetables in home gardens) will depend on whether the area in which they are located is found to be contaminated. Contamination would occur only if chemical agent droplets or particles were deposited on surfaces in an area as the chemical plume passed by. This is extremely unlikely to occur. However, in order to be certain public safety is protected, the CSEPP Planning Guidance calls for local and state authorities to move very quickly to quarantine the area they suspect may be contaminated. The quarantined area will probably be fairly large at the beginning because officials will want to be sure 
they include all areas that could possibly be contaminated. As testing shows that some areas were not actually contaminated, the size of the quarantine area will probably shrink. Once state and local health officials declare that a particular area did not receive contamination, garden produce in that area can be gathered and eaten or sold. In the unlikely event that produce in some areas is found to be contaminated, it will be destroyed to protect against the possibility of human exposure.

\section{If I relocate to an unaffected area after sheltering, how long will I have to stay away from my home?}

It is impossible to know how long each household that relocates will have to remain away. However, many people will probably be able to return relatively quickly. To be sure everyone is protected, emergency management officials will recommend shelter-in-place or evacuation for the largest area they believe could possibly be affected by the chemical agent release. Much of this area, if affected at all, will experience only agent vapor, which will dissipate quickly. These areas should be reopened soon, after monitoring teams confirm that no vapor or contamination remains. If the agent release involves mustard agent or nerve agent VX, samples will be collected to determine if lingering contamination is present on the ground or other surfaces. It may take from several days to a week before the data can be completely analyzed and the areas free from contamination can be reopened for residents to return. Any areas where contamination is found or suspected will remain closed until the remaining chemical agent degrades on its own or is removed by decontamination actions.

\section{Will contamination testing be performed to be sure it is safe for me to return to my home?}

Contamination testing will be conducted in all areas where there is a realistic chance that chemical agent may have been deposited on surfaces. (More detail is provided in the answer to the immediately preceding question.)

\section{Suppose I own a business in the affected area? Do the same things apply when ending shelter-in- place at a business? What should I do for my employees and customers in this case?}

The process of ending shelter-in-place at a business is essentially the same as that followed at a residence. People who have sheltered should follow the recommendations of emergency officials regarding what actions to take as they leave their shelters. If possible, business owners and managers may choose to provide employees and customers with the opportunity to shower and/or change into uncontaminated clothes. However, it is important to remember that everyone must complete these actions quickly. If emergency officials recommend relocation to an unaffected area after ending shelter-in-place, each business owner or manager should make sure that everyone who sheltered at the business leaves the premises.

\section{Does the type of facility or structure make a difference in whether or not I should relocate to an unaffected area after ending shelter-in-place?}

The type of building used as an in-place shelter has little to do with deciding whether to relocate to an unaffected area afterwards. The key factor in this decision is whether or not there is likely to be lingering chemical agent contamination or vapors in the area where people sheltered. This, in turn, depends on the type of agent released, the nature of the release (spill, fire, or explosion), and the weather conditions at the time. Emergency management officials will evaluate the chemical agent release characteristics and weather conditions at the time of a release. If they determine that lingering contamination or vapor is a possibility, they will recommend that people relocate after ending shelterin-place.

\section{Whom should I contact if I have questions or need further information or instructions?}

If you have any other questions about what to do when you end shelter-in-place, contact your local emergency management agency. 


\section{ACKNOWLEDGMENTS}

The author thanks John Sorensen, Annetta Watson, Marianne Rutishauser, and Michael Myirski for their helpful reviews of this paper. 


\section{REFERENCES}

Argonne National Laboratory 2001. When and How to End Shelter-In-Place Protection from a Release of Airborne Hazardous Material: Report on a Decision-Making Concept and Methodology, Chicago, IL. 
ORNL/TM-2003/230

INTERNAL DISTRIBUTION

1. T. R. Curlee

2. S. G. Hildebrand

3-27. B. L. Shumpert

28-52. J. H. Sorensen
53. B. M. Vogt

54. A. P. Watson

55-57. ESD Library

58. ORNL Center Research Library

59. ORNL Laboratory Records-RC

\section{EXTERNAL DISTRIBUTION}

60. Michael Myirski, U.S. Army SBCCOM, Aberdeen Proving Ground, Maryland 21010-5423

61. Robert Norville, CSEPP Training Manager, U.S. Department of Homeland Security, Washington, D.C. 20472

62. Marianne Rutishauser, Tooele County Emergency Management, 47 S. Main Street, Tooele, Utah 84074 